\title{
Short fiction writing in English by Chinese university students: An integrated F-A-I-T-H approach - CORRIGENDUM
}

\author{
GANG SUI
}

DOI: https://doi.org/10.1017/S0266078419000476 Published online by Cambridge University Press: 20 December 2019

The authors apologise that upon publication the funding information was missed off.

The author is grateful for the research funding from the Beijing Municipal Project of Social Sciences, China (20WXB009)

The online version of this article has been updated to include this information.

\section{Reference}

Sui, G. (2019). Short fiction writing in English by Chinese university students: An integrated F-A-I-T-H approach: How do Chinese university students use English in creative ways to 'write truly' while describing something fictional or 'untrue'? English Today, 1-7 